\title{
Synthesis of Azapterocarpan Analogues by Intramolecular 1,3-dipolar Cycloaddition
}

\author{
Júlio C. F. Barcellos, ${ }^{(a)}$; Ayres G.Dias, ${ }^{(b)^{*}}$; Paulo R. R.Costa ${ }^{(a) *}$ \\ a Laboratório de Química Bioorgânica, NPPN, Universidade Federal do Rio de Janeiro. Cidade Universitária, \\ 21941-590, Rio de Janeiro, Brasil. ${ }^{b}$ Departamento de Química Orgânica, Instituto de Química, Universidade \\ do Estado do Rio de Janeiro, R. São Francisco Xavier, 524, Maracanã, 20550-900, Rio de Janeiro, Brasil

\section{E-mail : ayres.dias@gmail.com ; prrcosta2011@gmail.com}

Keywords: aza pterocarpan, Intramolecular 1,3-dipolar cycloaddition,antiparasitic drugs, anticancer

\section{INTRODUCTION}

As part of a program directed at the discovery of new anticancer and antiparasitic drugs, our laboratory synthesized very promising new azapterocarpan analogues type $\mathbf{1}$, through a palladium catalyzed aza-arylation reaction (Figure 1). ${ }^{1}$ Now we are concentrating our efforts in the synthesis of analogues of 1, type 2-4, through intramolecular 1,3 dipolar cycloaddition, (1,3-IDC).
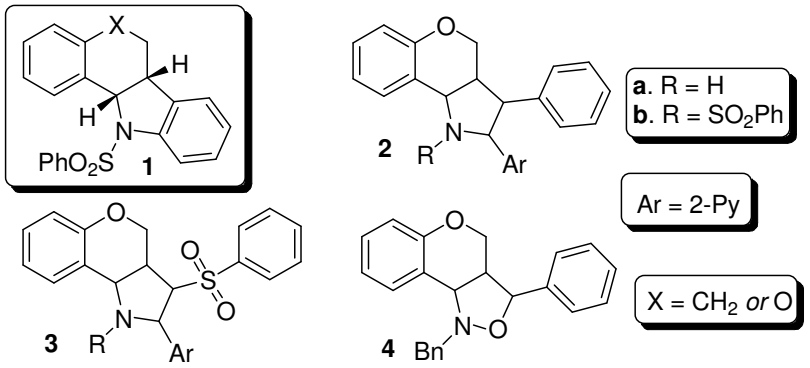

Figure 1. Azapterocarpans 1 and analogues.

\section{RESULTS AND DISCUSSION}

The strategies chosen to prepare the aza-analogues type 2-4 are shown in Scheme 1. In both cases the key step is an 1,3-IDC. The preliminary results obtained are shown in Scheme 2.

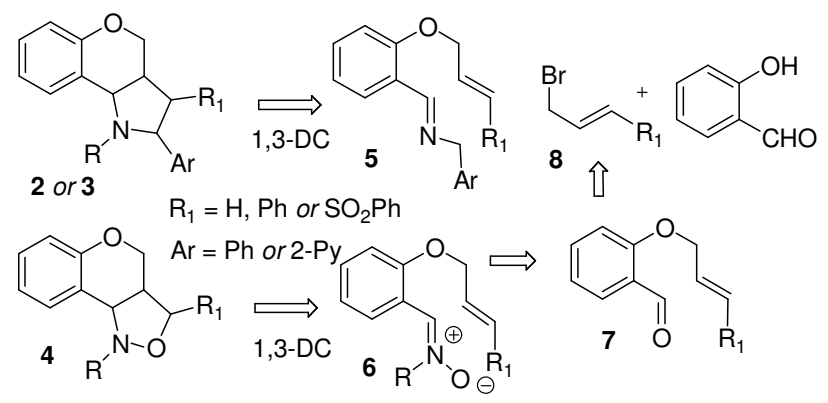

Scheme 1. Synthetic strategy to analogues type 2-4.

Salicylaldehyde was $O$-alkylated with allylic bromides, leading to 9 in excellent yield. These compounds were transformed into the corresponding $\mathrm{N}$-methylnitrones $\mathbf{1 0}$ and a thermal condensation leads a prototype 11 in $57 \%$ yields (non-optimized).

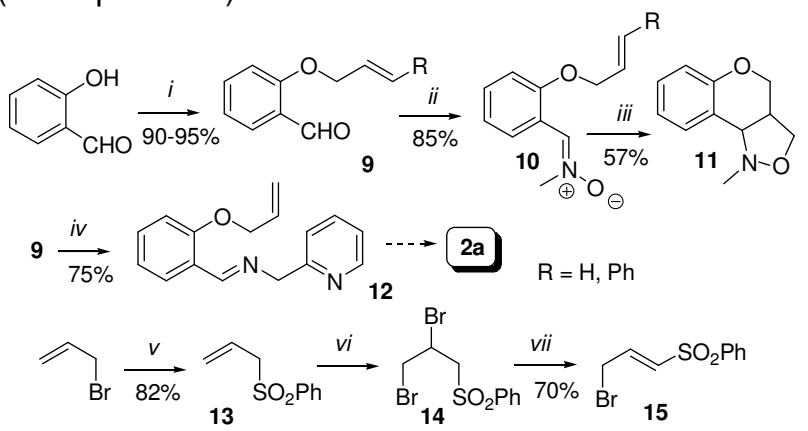

i. Bromide, Acetone, $\mathrm{K}_{2} \mathrm{CO}_{3} 60^{\circ} \mathrm{C}$, 2-6h; ii. $\mathrm{NH}_{2} \mathrm{OH}$. $\mathrm{HCl}$; TEA, $\mathrm{CH}_{2} \mathrm{Cl}_{2} \mathrm{Na}_{2} \mathrm{SO}_{4}$ 4h,r.t.; iii. Toluene, ref., 6 ; iv. DIPEA, 2- $\mathrm{PyCH}_{2} \mathrm{NH}_{2}$, MS $4^{\circ} \mathrm{A}$, 3d, r.t.; v. $\mathrm{PhSO}_{2} \mathrm{Na}$, DMF, 12 h, r.t.; vi. $\mathrm{Br}_{2}, \mathrm{CCl}_{4}$; vii. TEA, r.t.

Scheme 2. Studies toward the synthesis of 2-4.

The imines type 12 were obtained by Kurth methodology ${ }^{2}(75 \%)$ and employed in 1,3-IDC preliminary experiments. The metallo-azomethine ylides, generated by reaction of imine with DBU in combination with $\mathrm{LiBr}^{3}{ }^{3}$ were studied in thermal and microwave-assisted experiments to obtained 2a. The allylic sulphone 15 was most conveniently obtained from $S$-alkylation/bromination of allyl bromide followed by dehydrobromination using TEA, Scheme 2. This bromide will be use in 1,3 IDC reactions to prepare 3 analogues. Work is now in progress to establish the relative configuration in $\mathbf{1 1}$ and accomplish others 1,3-DC reactions.

\section{CONCLUSION}

The 1,3-IDC reaction is a rapid and practical approach to Aza-pterocarpan and analogues skeletons.

\section{ACKNOWLEDGEMENTS}

FAPERJ, CNPq, CAPES.

\section{REFERENCES}

Djenne, B.C. PhD Thesis, NPPN-UFRJ, December 2010, Costa, P.R.R.

et all J. Braz. Chem. Soc. 2009, 20,1916.

${ }^{2}$ Kurth, M.J. et all, J. Org. Chem. Soc. 1998, 63, 3081

${ }^{3}$ Grigg, R. et all, Tetrahedron. 1995, 51, 273.

$14^{\text {th }}$ Brazilian Meeting on Organic Synthesis $-14^{\text {th }}$ BMOS - September 01-05, 2011-Brasilia, Brazil 